\title{
A Simplified Process Engineering Model for Evaluation of Biomass Gasification Performance via Mass/Energy Balances as Modeled Using a Spreadsheet Platform
}

\author{
John L Guillory ${ }^{1}$, Prashanth R Buchireddy ${ }^{1}$, Stanislav O Barskov ${ }^{2}$ and Mark E Zappi ${ }^{2}$ \\ ${ }^{1}$ Department of Mechanical Engineering, UL Energy Institute, University of Louisiana at Lafayette, USA \\ ${ }^{2}$ Department of Chemical Engineering, UL Energy Institute, University of Louisiana at Lafayette, USA
}

\begin{abstract}
This paper documents a simplified process model developed in connection with the Biomass Gasification Development program at the University of Louisiana at Lafayette. The numerical solution to the set of non-linear simultaneous equations arising from the analysis was implemented using the "Solver" feature of MS Excel ${ }^{\circledR}$. It is designed to provide a rational first-pass basis for reactor sizing and process equipment selection yet is accessible and readily modifiable by a process engineer with an average programming background. The results follow trends with respect to the important variables (temperature, feedstock composition, etc.) in general agreement with experimental data reported for well-mixed, relatively isothermal reactors such as bubbling and circulating fluidized beds. The model generally overestimates the quantitative $\mathrm{H}_{2} / \mathrm{CO}$ ratio reported for most gasifiers which results in an underestimation of the product density. However, this does not appear to have a strong influence on energy factors (e.g., the gasifier chemical energy efficiency) and is considered sufficiently accurate for initial design and selection of gasification system components.
\end{abstract}

Keywords: Biomass gasification; Alternative energy; Process modelling; Sustainable systems

\section{Introduction}

Gasification is the process of converting combustible materials (often biomass and coal) via oxygen-starved conditions within an engineered reactor into synthesis gas as the targeted chemical product [1-4]. Synthesis gas (aka. syngas) is an industrial gas primarily composed of hydrogen, carbon monoxide, carbon dioxide, and methane [4] which typically has an energetic value in the $100-300 \mathrm{btu} / \mathrm{cf}$ range $[3,5]$. Over the past few years, gasification has received a lot of developmental attention as a means of producing transportation fuels via catalysis [6]; primary alcohols using fermentation [7] or catalytic conversion [8]; electrical power via production of steam or direct feed of the syngas into a genset [9]; hydrogen for later use as a burnable fuel or chemical feedstock $[4,10]$. In all of these applications, the quality of the syngas in terms of thermal value and level of impurities are of key concern as the syngas is used to produce energy and/or chemicals. Numerous gasifier designs have been proposed and found to be effective while operating under a variety of conditions as reviewed by Sadaka [3] and Breault [11]. In essence, the gasifier provides a thermal platform for the degradation of biomass and/or coal (carbon-based feedstocks into basic chemical constituents found in syngas $\left(\mathrm{H}_{2}, \mathrm{CO}, \mathrm{CO}_{2}\right.$, and $\left.\mathrm{CH}_{4}\right)$. From the syngas, the chemicals can be reconfigured into value-added products or burned directly as an alternative fuel for combustion or engine operations. Thus, gasification offers a forgiving process that can take a variety of feedstocks with additional flexibility for endproduct selection (fuels vs. chemicals). For these reasons, gasification continues to be of great interest to those stakeholders interested in commercializing renewable energy sources or the expanded use of coal for industrial purposes.

The design of gasification reactors and other components (piping, compressors, etc.) is usually based on residence times, plug-flow velocities and similar empirical "good-practice" parameters. In order for the engineering design to be cost-effective, one normally chooses a calculation scheme which, though not necessarily representing the precision of the latest research tool, is sufficiently representative of the process to give reasonable approximations of flow rates, densities, energy availability, power requirements along with being simple for most designers to follow the mechanistic logic (allowing them to make changes to the program) and capable of being run on a PC. Thus, it is desirable to use a model in which the thermodynamics as well as the numerical implementation is sufficiently accessible to allow the engineer to modify it to fit any unique aspects of the particular design.

In the case of energy processes carried out under either excessoxidant or mildly oxidant-deficient conditions, such as typical combustion, the "Complete Combustion" model is quite simple and satisfactory for most design purposes [12]. In this model, each of the major reactive fuel elements is assumed to form only one product constituent; e.g., $\mathrm{C} \rightarrow \mathrm{CO}_{2} ; \mathrm{H} \rightarrow \mathrm{H}_{2} \mathrm{O}$, etc., and the composition is substantially independent of temperature. Any oxygen not represented in one of these "permanent" gases and all nitrogen (either from the fuel or the oxidant stream) is assumed to emerge in their diatomic forms, $\mathrm{O}_{2}$ and $\mathrm{N}_{2}$. The energy balance based on this mass balance model is likewise simple, requiring only that one has (or can approximate) a heating value of the fuel. If the reactor temperature is specified, the energy equation can be solved to give the required excess air; conversely, a specified excess air will yield a resulting temperature, albeit usually requiring an iterative scheme to accurately account in the variation of specific heats with temperature.

Gasification processes present a more complex problem in that the deficiency of an oxidant results in distribution of each fuel element over a range of compounds (e.g., $\mathrm{C} \rightarrow \mathrm{C}, \mathrm{CO}, \mathrm{CO}_{2}, \mathrm{CH}_{4} ; \mathrm{H} \rightarrow \mathrm{H}_{2}, \mathrm{H}_{2} \mathrm{O}, \mathrm{CH}_{4}$, etc.) and that distribution, unlike combustion, is strongly related to

${ }^{*}$ Corresponding author: Mark E Zappi, Department of Chemical Engineering, UL Energy Institute, University of Louisiana at Lafayette, USA, Tel: 337-482-6686; E-mail: zappi@louisiana.edu

Received November 10, 2015; Accepted November 24, 2015; Published November 30, 2015

Citation: Guillory JL, Buchireddy PR, Barskov SO, Zappi ME (2015) A Simplified Process Engineering Model for Evaluation of Biomass Gasification Performance via Mass/Energy Balances as Modeled Using a Spreadsheet Platform. J Bioprocess Biotech 5: 263 doi:10.4172/2155-9821.1000263

Copyright: (c) 2015 Guillory JL, et al. This is an open-access article distributed under the terms of the Creative Commons Attribution License, which permits unrestricted use, distribution, and reproduction in any medium, provided the original author and source are credited. 
Citation: Guillory JL, Buchireddy PR, Barskov SO, Zappi ME (2015) A Simplified Process Engineering Model for Evaluation of Biomass Gasification Performance via Mass/Energy Balances as Modeled Using a Spreadsheet Platform. J Bioprocess Biotech 5: 263 doi:10.4172/21559821.1000263

Page 2 of 5

the reaction temperature. In mathematical terms, the mass and energy balances are "coupled" and, to make matters more complex, even the simplest realistic models of the gasification process such as proposed here are non-linear thus eliminating the common explicit methods of simultaneous solution.

With gasification being a complex and dynamic process, several models have been developed by other researchers considering a wide range of assumptions and different outputs. Typically, gasification modelling has been classified into either thermodynamic equilibrium modelling or kinetic modelling. Mathieu and Dubuisson [13], Doherty et al. [14] and $\mathrm{Ng}$ et al. [15] each developed thermodynamic equilibrium models based on either stoichiometric or non-stoichiometric equilibrium. Mathieu and Dubuisson [13] proposed a thermodynamic equilibrium model based on minimization of Gibbs free energy and was simulated using Aspen Plus. The model incorporated pyrolysis, combustion, the Boudouard Reaction, and the gasification processes. They studied the effect of oxygen factor, air temperature, and oxygen content in air, operating pressure, and the injection of steam on gasification process efficiency. Minimization of Gibbs free energy model was also employed by Doherty et al. [14] who used the model to study the effect of temperature, equivalence ratio, air preheating, biomass moisture and steam injection on syngas composition, heating value, and conversion efficiency. Their model incorporated three sub-models for drying and pyrolysis, partial oxidation, and gasification. $\mathrm{Ng}$ et al. [15] developed a stoichiometric equilibrium model of biomass fluidized bed gasifier to predict syngas composition for different types of biomass feedstocks. The model incorporated endothermic Boudouard equilibrium, methane decomposition, and heterogeneous water-gas shift reactions and exothermic hydrogenating gasification and water-gas shift reactions. Lingo 13.0 with Global solver comprising of Branch-and-Bound (B\&B) algorithm combined with linearization was used to find globally optimal solutions to Non-Linear Programming (NLP). Nikoo and Mahinpey [16], Beheshti et al. [17] and Nilsson et al. [18] developed kinetic models which were solved used Aspen Plus. Nikoo and Mahinpey [16] developed a model for biomass gasification in an atmospheric pressure fluidized bed gasifier that treated both hydrodynamic and reaction kinetics simultaneously assuming a steady state isothermal process, instantaneous biomass devolatilization, and that fluidized bed reactor is divided into two regions: bed and freeboard. The model predicted the effects of temperature, equivalence ratio, steam to biomass ratio, and biomass particle on gas composition. Beheshti et al. [17] developed a model that incorporated chemical reaction rates, empirical correlations of pyrolysis yields, and hydrodynamic properties. The model predicted syngas composition, char yield, and tar concentration during the airsteam gasification of biomass. Nilsson et al. [18] developed a steadystate model, which comprised of four sub-models including fluidized bed devolatilizer, seal, non-catalytic gas reformer, and char converter. The model predicted the effect of temperature and equivalence ratio on carbon conversion, tar conversion, and composition of syngas in sewage sludge fluidized bed gasification.

Modern spreadsheets provide a number of general computational subroutines that can be easily incorporated into a design tool by the average process engineer who has neither the interest nor time to develop both the process analysis and the underlying computational code. This paper will illustrate the application of the MS Excel" "Solver" feature to biomass gasification process analysis and present some sample results. The over-arching goal of this effort was to develop and verify a model that design engineers can utilize to predict system performance with varying inputs with particular interest in syngas energetic and chemical compositional prediction.

\section{Summary of Analysis}

\section{Major assumptions}

- In the absence of a specific reactor description, thermochemical equilibrium principles provide a satisfactory firstpass approximation of common gaseous product reactions in biomass gasification applications

- All gas-solid reactions (with the exception of an empirical char allowance) go to completion

- Combustible constituents in gaseous product other than $\mathrm{CO}$, $\mathrm{H}_{2}$ and $\mathrm{CH}_{4}$ are negligible

- Negligible free oxygen exists in gaseous product

- Ideal Gas behavior

- No external air preheat, feedstock drying and/or heating

\section{Description of feedstock composition}

In accordance with normal US laboratory practice, the moisture content of the feedstock is assumed to be available on an as-received weight basis ("w/w a-r") and the major organic elements on a dry weight basis ("w/w d"). Only three elements (C, H and O) are considered and the ash is calculated by difference. If the analysis includes other elements (e.g., $\mathrm{N}$ ), it is recommended that these be included with the oxygen fraction, otherwise it will be included in the ash analysis and potentially overestimate the dust loading in the product gas.

\section{Adjustment of feedstock properties to account for char formation}

The analysis allows specification of an empirical carbonaceous char and/or tar formation allowance $\mathrm{F}_{\text {chr }}$ expressed as a fraction of the dry carbon content $\mathrm{mf}_{\mathrm{C}, \mathrm{d}}$ of the feedstock $\left[\mathrm{R}_{1}\right]$. The following adjustment in carbon is made when converting the composition to and a-r basis,

$$
\mathrm{mf}_{\mathrm{C}, \mathrm{a}-\mathrm{r}}=\mathrm{mf}_{\mathrm{C}, \mathrm{d}}\left(1-\mathrm{mf}_{\mathrm{H}_{2} \mathrm{O}, \mathrm{a}-\mathrm{r}}\right)\left(1-\mathrm{F}_{\text {char }}\right)
$$

The unreacted char solids are included with the ash by difference.

The energy balance is based on enthalpies of formation. Since biomass feedstocks are complex mixtures for which, at best, only the Higher Heating Value (hhv) is usually known $\left[R_{2}\right]$, the enthalpy of formation of the feedstock is computed by,

$$
\mathrm{h}_{\mathrm{f}, \text { fuel, a-r }}^{0}=\mathrm{hhv}_{\text {fuel, }}\left(1-\mathrm{mf}_{\mathrm{H}_{2} \mathrm{O}, \mathrm{a}-\mathrm{r}}\right)+\frac{\mathrm{mf}_{\mathrm{C}, \mathrm{a}-\mathrm{r}}}{12} \mathrm{~h}_{\mathrm{f}, \mathrm{CO}_{2}}^{0}+\frac{\mathrm{mf}_{\mathrm{H}, \mathrm{a}-\mathrm{r}}}{2} \mathrm{~h}_{\mathrm{f}, \mathrm{H}_{2} \mathrm{O}(\mathrm{L})}^{0}
$$

Where, the estimation of $\mathrm{CO}_{2}$ is based on the reduced availability of carbon due to deducting the char allowance. Note that this is an approximation since any energy impact associated with the formation of char from feedstock is neglected in subsequent calculations. This is thought to be satisfactory in the temperature ranges of interest where char formation represents a relatively small fraction of the total mass balance.

\section{Product enthalpies}

Since the process design of gasifiers normally starts with a specified temperature, enthalpies of the gaseous products can be hand-entered from tables readily available in many standard references. However, it 
Citation: Guillory JL, Buchireddy PR, Barskov SO, Zappi ME (2015) A Simplified Process Engineering Model for Evaluation of Biomass Gasification Performance via Mass/Energy Balances as Modeled Using a Spreadsheet Platform. J Bioprocess Biotech 5: 263 doi:10.4172/21559821.1000263

Page 3 of 5

is far more convenient to incorporate an algorithm based on the Ideal Gas approximation,

$$
\mathrm{h}_{\mathrm{T}, \mathrm{i}}-\mathrm{h}_{0}=\int_{\mathrm{T}_{0}}^{\mathrm{T}} \overline{\mathrm{C}}_{\mathrm{P}, \mathrm{i}} \mathrm{dT}
$$

Where, $\bar{C}_{P, i}$ is a polynomial expression for the molar specific heat at constant pressure for each gaseous component "i" as a function of temperature; such correlations are also readily available. Empirical correlations suggested by Sonntag, Borgnakke and Van Wylen resulted in enthalpy deviations of less than $0.6 \%$ compared to independent tabular values in the same reference [19].

\section{Equilibrium constants}

The equilibrium composition was based on two mass action equations that incorporate the five major reaction products addressed in this simplified analysis (nitrogen is assumed to be a non-reactive diluent). For the Water Gas Shift Reaction,

$$
\begin{gathered}
\mathrm{CO}+\mathrm{H}_{2} \mathrm{O} \Leftrightarrow \mathrm{CO}_{2}+\mathrm{H}_{2} \\
\mathrm{~K}_{\mathrm{P}, \mathrm{WGS}} \text { deduced from JANAF data [20] is } \\
K_{P, W G S}=\exp [66.005-10.382 \ln (T+273)+0.00603(T+273)]
\end{gathered}
$$

Where, $\mathrm{T}$ is the reaction temperature in ${ }^{\circ} \mathrm{C}$. The standard deviation of the ratio of the tabulated to calculated $\mathrm{K}_{\mathrm{p}}$ 's for 14 data points over the range of $350-1050^{\circ} \mathrm{C}$ from which the correlation was deduced is less than $2 \%$.

For the steam reforming reaction,

$$
\mathrm{CH}_{4}+\mathrm{H}_{2} \mathrm{O} \Leftrightarrow \mathrm{CO}+3 \mathrm{H}_{2}
$$

$\mathrm{K}_{\mathrm{P}, \mathrm{SR}}$ correlation was,

$K_{P, S R}=\exp \left[-841.17+215.88 \ln (T+460)-13.709(\ln (T+460))^{2}\right]$

The standard deviation of the published values for 14 data points, referenced to the calculated value, is about $3.7 \%$ for the same temperature range quoted above.

\section{Residual equations}

The conceptual molar balance for the reaction is,

$$
\begin{aligned}
& \mathrm{n}_{\mathrm{C}} \mathrm{C}+\mathrm{n}_{\mathrm{H}} \mathrm{H}+\mathrm{n}_{\mathrm{O}} \mathrm{O}+\mathrm{n}_{\mathrm{M}} \mathrm{H}_{2} \mathrm{O}(\mathrm{L})+\mathrm{n}_{\mathrm{O}_{2}} \mathrm{O}_{2}+\mathrm{n}_{\mathrm{N}_{2}} \mathrm{~N}_{2} \Rightarrow \\
& \mathrm{n}_{\mathrm{CO}} \mathrm{CO}+\mathrm{n}_{\mathrm{CO}_{2}} \mathrm{CO}_{2}+\mathrm{n}_{\mathrm{H}_{2}} \mathrm{H}_{2}+\mathrm{n}_{\mathrm{H}_{2} \mathrm{O}} \mathrm{H}_{2} \mathrm{O}(\mathrm{v})+\mathrm{n}_{\mathrm{N}_{2}} \mathrm{~N}_{2}+\mathrm{n}_{\mathrm{CH}_{4}} \mathrm{CH}_{4}
\end{aligned}
$$

Where, the stoichiometric coefficients $n_{i}$ are interpreted, for purposes of subsequent solution, as moles per unit mass of a-r feedstock. The coefficients $\mathrm{n}_{\mathrm{O}_{2}}$ and $\mathrm{n}_{\mathrm{N}_{2}}$ on the reactant side represent the oxidant mixture (NOT necessarily atmospheric air).

The conceptual energy balance is,

$$
h_{f, f u e l, a-r}^{0}+n_{M} h_{f, H_{2} O(L)}^{0}-F_{H L}\left(h h v_{f u e l, d}\right)=\sum_{P} n_{i}\left(h_{f}^{0}+\left[h_{T}-h_{O}\right]\right)_{i}
$$

Where, $\mathrm{F}_{\mathrm{H}}$ is a heat loss allowance, expressed as a fraction of the dry hhv $\left[\mathrm{R}_{3}\right]$. Note that the enthalpy of formation of the liquid moisture on the fuel is treated separately from liquid moisture formed from the combustion of hydrogen in calorimeter measurement of the hhv.

The equilibrium model for the Water Gas Shift Reaction is,

$$
K_{P, W G S}=\frac{n_{\mathrm{CO}_{2}} n_{\mathrm{H}_{2}}}{n_{\mathrm{CO}} n_{\mathrm{H}_{2} \mathrm{O}}}
$$

and for the Steam Reforming Reaction $\left[\mathrm{R}_{4}\right]$,

$$
K_{P, S R}=\frac{n_{C O} n_{H_{2}}{ }^{3}}{n_{C H_{4}} n_{H_{2} O}}\left[\frac{P / P_{0}}{\sum_{P} n_{i}}\right]^{2}
$$

Note, since the system is to be designed for a specified molar oxygen concentration in the oxidant mixture $\left(\mathrm{f}_{\mathrm{O}_{2}}\right)$, oxygen and nitrogen are not independent, i.e.,

$$
\left.\frac{\mathrm{n}_{\mathrm{N}_{2}}}{\mathrm{n}_{\mathrm{O}_{2}}}\right]_{\text {Oxidant }}=\frac{1}{\mathrm{f}_{\mathrm{O}_{2}}}-1
$$

six independent equations (the $\mathrm{C}, \mathrm{H}$ and $\mathrm{N}$ elemental balances, two equilibrium equations and the energy balance) incorporating six variables $\mathrm{n}_{\mathrm{CO}}, \mathrm{n}_{\mathrm{CO}_{2}}, \mathrm{n}_{\mathrm{H}_{2}}, \mathrm{n}_{\mathrm{H}_{2} \mathrm{O}}, \mathrm{n}_{\mathrm{CH}_{4}}$ and $\mathrm{n}_{\mathrm{N}_{2}}$ can be written. These were recast in residual form, normalized and solved using the MS Excel "Solver" feature $\left[\mathrm{R}_{5}\right]$.

\section{Starting values for numerical solution}

In order to avoid the numerous solution sets which have no physical meaning, it is necessary that an initial estimate near the meaningful solution be established. For purposes of this analysis, a simple, somewhat arbitrary set of values were calculated which satisfy the mass balance:

- The carbon from the adjusted ultimate analysis was distributed to $\mathrm{CO}_{2} / \mathrm{CO} / \mathrm{CH}_{4}$ in the molar ratio $0.65 / 0.34 / 0.01$

- All hydrogen in the feedstock was assigned to $\mathrm{H}_{2}$ in the products

- All liquid water in the feedstock was assigned to water vapor in the products

- The atmospheric nitrogen that would have been associated with the stoichiometric combustion of the feedstock was assigned to the products

These starting values were found to result in satisfactory convergence for most cases of practical interest; however, the recommended starting values should be incorporated into the spreadsheet in such a way that they can be easily overridden by the user in the event that convergence problems are encountered.

\section{Elimination of meaningless results}

Fortunately, it is relatively simple to identify most physically meaningless solution sets, either automatically or manually, by examining the sign of each member of the set. Since the solution members represent the "moles per unit mass of feedstock" of each component, a negative value indicates convergence to a meaningless solution and requires the run be repeated with another set of starting values. It is, however, less common but nevertheless possible to "converge", at least within the specified convergence criteria, to a set of inaccurate positive roots. This is usually indicated by an examination of residuals displayed by the "Solver" routine rather than the roots themselves. It was observed that, over a fairly wide range of feedstocks, temperatures, etc., "good" solutions usually resulted in normalized residuals of $10^{-3}$ or less for the individual equations and a sum-ofsquares residual of $10^{-6}$ or less for the entire set. In the event that questionable convergence is noted, it is best to rerun the case at several different temperatures and examine the trend for discontinuities or random behavior. Errors of this type are often encountered when one 
of the solution set members (usually the methane) becomes vanishingly small compared to the others. This can sometimes be overcome by changing the "Solver" operational parameters (e.g., increasing the maximum number of iterations allowed) but is usually best handled by changing the starting values. The special case of low $\mathrm{CH}_{4}$ at elevated temperatures is discussed below.

\section{Special provisions for unsatisfactory convergence at low methane concentrations}

Generally, the solution to these equations presented is relatively stable so long as the values are not dramatically different numerically. However, it happens that, while $\mathrm{H}_{2}$ and $\mathrm{CO}$ quantities are typically of comparable magnitudes throughout the temperature range of practical interest, $\mathrm{CH}_{4}$ is comparable in magnitude only in the lower end of the range. Depending upon feedstock composition and char allowance, predicted (and, to a large extent, observed) $\mathrm{CH}_{4}$ production becomes quite small usually around $550-700^{\circ} \mathrm{C}$. This often not only causes the overall solution to become especially sensitive to starting values but also compromises the convergence of the other, larger components in an ultimately futile attempt to reach convergence of the small $\mathrm{CH}_{4}$ value. This behavior can be observed by pushing the solution to higher temperatures and plotting the result; while the $\mathrm{CH}_{4}$ value will continue to be accurate in a practical, semi-quantitative sense (i.e., small), there will be a random "wandering" of the other components at different starting values and convergence criteria. Although this behavior tends to occur at high temperatures that are often of limited practical interest due to the corresponding low gasification efficiency, it is easily avoided by simply assigning a zero value to the $\mathrm{CH}_{4}$. Mathematically, this amounts to solving five rather than six simultaneous equations, i.e., eliminating the Steam Reforming equilibrium relationship and assigning $\mathrm{CH}_{4}$ to be zero elsewhere in the remaining equations; the solution procedure is identical. It will be found that both analyses will at some temperature substantially agree; the most reliable solutions above that temperature will be those developed with the 5-equation model whereas, below that temperature, the 6-equation model is most appropriate.

\section{Results}

Figure 1 illustrates the predicted concentrations of the combustible species produced in the gasification of White Cedar containing 35\% moisture using atmospheric air as the oxidant. Note that the $\mathrm{CH}_{4}$ concentration predicted by the 6 -equation model was quite low $(<<1 \%)$ by $650^{\circ} \mathrm{C}$, thereby representing a negligible contribution to the total combustible energy at that point. In order to avoid instabilities in the mathematical solution (which became quite pronounced around 750 $800^{\circ} \mathrm{C}$ ), the 5-equation solution for $\mathrm{CO}$ and $\mathrm{H}_{2}$ was invoked at $650^{\circ} \mathrm{C}$. It is noted that there is a smooth transition between the two solutions. The trend of the combustibles beyond that point proceeds as expected as stoichiometric combustion (non-gasification) is approached in the mid- $1000^{\circ} \mathrm{C}$ range.

\section{Comparison of simplified model to observations}

Prediction of the precise product composition for most chemical process reactor designs requires a far more sophisticated kinetic and fluid flow model than a simple first-principles equilibrium model such as that presented here can be expected to accomplish. However, experienced process engineers often prefer to compare their design models to performance measurements and deduce useful adjustments and corrections to the simple models rather than continually incorporate ever more sophisticated, unwieldy models into their day-

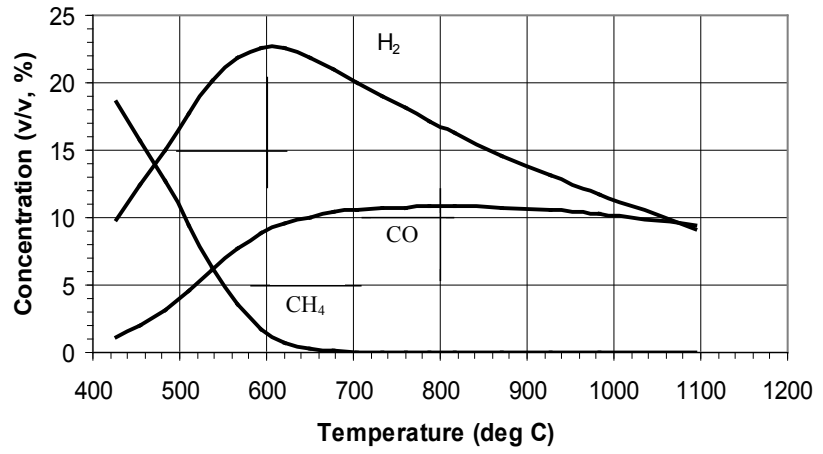

Figure 1: Combustible Component Concentrations in Air Gasification of White Cedar Feedstock (35\% w/w Moisture, 1\% Char Allowance, No Heat Loss, 1.0 atm)

to-day practice. In the case of biomass gasification, a broad, reliable body of data [21-23] is available against which to compare models such as this. Detailed comparisons are beyond the scope of this paper but the following qualitative generalizations can be made.

- The model is best applied to more-or-less isothermal reactors such as bubbling or circulating fluidized beds, entrained reactors, etc. in which a single, unambiguous reaction temperature can be assigned.

- In counter flow devices where the product gas potentially devolatilizes fresh feedstock immediately before leaving the reactor, the model (lumping, as it does, all hydrocarbons into methane) underestimates total hydrocarbon content significantly.

- The equilibrium model overestimates the $\mathrm{H}_{2} / \mathrm{CO}$ ratio in most cases and therefore likewise underestimates the molecular weight (and density) of the products. This may also be a consideration in Fischer-Trope liquids applications.

- The estimate of product heating value on a mass basis is relatively good but, due to the underestimate of density, often underestimates heating value on a volume basis.

- $\quad$ Relegating char to a simple estimated allowance (usually a few per cent of the carbon input) appears reasonable for intermediate and high temperatures (above about $650-700^{\circ} \mathrm{C}$ ) but may compromise its usefulness at exceptionally low temperatures (say, below $550^{\circ} \mathrm{C}$ ).

\section{Discussion and Conclusions}

The results follow trends with respect to the important variables (temperature, feedstock composition, etc.) in general agreement with experimental data reported for well-mixed, isothermal gasification reactors. The model generally overestimates the quantitative $\mathrm{H}_{2} / \mathrm{CO}$ ratio reported for most gasifiers which results in an underestimation of the product density. This does not appear to have a strong influence on energy factors (e.g., the gasifier chemical energy efficiency) and is considered sufficiently accurate for first-pass design and selection of gasification system components. However, it should be noted that the underestimation of density will cause, among other things, an overestimation of velocities (possibly important in certain reactors such as fluidized beds). Likewise, it will cause an overestimation in product flow and an underestimate in product heating value per unit of volume, not because of a significant inaccuracy in the energy balance but merely due to the lowered density creating a dilution effect. If the heating value of the gas produced is recast in, say, terms of unit mass of 
Citation: Guillory JL, Buchireddy PR, Barskov SO, Zappi ME (2015) A Simplified Process Engineering Model for Evaluation of Biomass Gasification Performance via Mass/Energy Balances as Modeled Using a Spreadsheet Platform. J Bioprocess Biotech 5: 263 doi:10.4172/21559821.1000263

Page 5 of 5

original a-r feedstock (i.e., a sort of gasifier efficiency), it is sufficiently close to most empirical measurements to be satisfactory for initial design purposes [24]

For the case of White Cedar modeling as reported this paper, methane production was found to be low (which is often the target), while the two key gas components, hydrogen and carbon monoxide, were generally present at the 2:1 molar ratio up to a temperature of $800^{\circ} \mathrm{C}$. This ratio is often considered ideal for syngas conversion within Gas-to-Liquids (GTL) systems. The $\mathrm{T}=650^{\circ} \mathrm{C}$ transition of the model into the 5-Equation Model appeared smoothly indicating solid fit and good utility for evaluating system performance. The results also indicated a better model fit for isothermal systems. Additionally, product heating values were better predicted using mass basis over volume basis reporting. However, the performance and use of the model were both deemed of good value and indicating that this modeling approach should be useful to design engineers as they evaluate various system construction and operation options.

It is further concluded that use of the MS Excel "Solver" feature is a convenient means of modeling biomass gasification for purposes of initial process design. Modifications to suit particular process designs (steam injection, oxidant preheat, reactor pressure, etc.) are easily incorporated with little or no sophisticated numerical programming. If used in conjunction with reasonable gasification process familiarity and judgment, it is a reliable engineering tool.

$\mathrm{R}_{1}$ : Although strongly influenced by oxidant type and reactor design, it is typically small (on the order of 1-3\%) in well-mixed, relatively isothermal reactors such as fluidized beds [21].

$\mathrm{R}_{2}$ : If a measured value of the hhv is not available, there are a number of empirical formulas relating hhv to the ultimate analysis. The Dulong Formula is arguably the best known of these although the Vondracek Formula is usually considered the most accurate for highoxygen materials such as biomass [24].

$\mathrm{R}_{3}$ : Heat loss allowances are notoriously difficult to estimate until later in the design process when reactor dimensions, materials, etc. have been identified. Generally, in industrial-scale units, $\mathrm{F}_{\mathrm{HL}}$ is often on the order of only $1-2 \%$ but may be $10 \%$ or greater in pilot or laboratory scale reactors.

$\mathrm{R}_{4}$ : For example, ordinary atmospheric air $\left(\mathrm{f}_{\mathrm{O}}=0.21\right)$ yields a value of 3.76 mo $\mathrm{N}_{2} / \mathrm{mo} \mathrm{O}_{2}$, a constant commonly invoked in elementary stoichiometry involving air.

$\mathrm{R}_{5}$ : "Residual Normalized" refers to the following generic algebraic transformation:

$$
\mathrm{A}+\mathrm{B}=\mathrm{C}+\mathrm{D} \Rightarrow \mathrm{R}_{\mathrm{N}}=\frac{\mathrm{C}+\mathrm{D}}{\mathrm{A}+\mathrm{B}}-1\left[\mathrm{R}_{\mathrm{N}} \rightarrow 0\right] \text { at convergence }
$$

\section{References}

1. Maschio G, Lucchesi A, Stoppato G (1994) Production of syngas from biomass. Bioresour Technol 48: 119-126.

2. Wu J, Fang $Y$, Wang $Y$ (2005) Combined Coal Gasification and Methane Reforming for Production of Syngas in a Fluidized-Bed Reactor. Energy Fuels 19: $512-516$

3. Sadaka S (2009) Gasification, Producer Gas and Syngas. Agriculture and Natural Resources Report No. FSA1051, University of Arkansas Division of Agriculture, Fayetteville, AK.

4. Lui K, Song C, Subramani V (2009) Hydrogen and Syngas Production and Purification Technologies. John Wiley \& Sons, Hoboken, NJ, USA

5. US Department of Energy (2015) Syngas Composition for IGCC. NETL (National Energy Technology Laboratory-DOE).
6. Yung MM, Jablonski WS, Magrini-Blair KA (2009) Review of catalytic conditioning of biomass-derived syngas. Energy Fuels 23: 1874-1887.

7. Munasinghe P, Khanal S (2009) Biomass-derived syngas fermentation into biofuels: Opportunities and challenges. Bioresour Technol 101: 5013-5022.

8. Subramani V, Gangwal S (2008) A Review of Recent Literature to Search for an Efficient Catalytic Process for the Conversion of Syngas to Ethanol. Energy Fuels 22: 814-839.

9. Wang L, Weller C, Jones D, Hanna M (2007) Contemporary issues in therma gasification of biomass and its application to electricity and fuel production. Biomass Bioenergy 32: 573-581.

10. Chaudhari S, Dalai A, Bakshi N (2003) Production of Hydrogen and/or Syngas $\left(\mathrm{H}_{2}+\mathrm{CO}\right)$ via Steam Gasification of Biomass-Derived Chars. Energy Fuels 17 1062-1067.

11. Breault R (2010) Gasification Processes Old and New: A Basic Review of the Major Technologies. Energies 3: 216-240.

12. Campbell AS (1985) Thermodynamic Analysis of Combustion Engines. R.E. Krieger Publishing Company. Technology \& Engineering, 366 pages.

13. Mathieu P, Dubuisson $R$ (2002) Performance analysis of a biomass gasifier. Energy Conversion and Management 43: 1291-1299.

14. Doherty W, Reynolds A, Kennedy D (2009) The effect of air preheating in a biomass CFB gasifier using ASPEN Plus simulation. Biomass Bioenergy 33: 1158-1167.

15. Ng RTL, Tay DHS, Ghani WAWK, Ng DKS (2013) Modeling and optimization of biomass fluidized bed gasifier. Appl Therm Eng 61: 98-105.

16. Nikoo MB, Mahinpey N (2008) Simulation of biomass gasification in fluidized bed reactor using ASPEN PLUS. Biomass Bioenergy 32: 1245-1254.

17. Beheshti S, Ghassemi H, Shahsavan-Markadeh R (2015) Process simulation of biomass gasification in a bubbling fluidized bed reactor. Energy Conversion and Management 94: 345-352.

18. Nilsson S, Gómez-Barea A, Fuentes-Cano D, Ollero P (2012) Gasification of biomass and waste in a staged fluidized bed gasifier: Modeling and comparison with one-stage units. Fuel 97: 730-740.

19. Sonntag RE, Borgnakke C, Van Wylen GJ (2006) Fundamentals of Thermodynamics. 5th ed. John Wiley \& Sons, Publishing Co., Hoboken, NJ, USA.

20. Stull D, Prophet H (1971) JANAF Thermochemical Tables, NSRDS-NBS37, US Department of Commerce, US Government Printing Office, Washington, DC, USA.

21. Guillory J, Goldbach S (1986) Production of Intermediate Heating Value Gas from Municipal Solid Waste via Oxygen-Blown Fluidized Bed Gasification. Proceedings of ASME Waste Processing Conference, Denver, Colorado.

22. Safitri A (2005) Biomass gasification using bubbling fluidized-bed gasifier investigation of the effect of different catalysts on tar reduction. Master Thesis Technische Universiteit Eindhoven.

23. Bain R (2004) An Introduction to Biomass Thermochemical Conversion National Renewable Energy Laboratory. US Department of Energy.

24. Green D, Perry R (2007) Perry's Chemical Engineers Handbook, 8th edn McGraw-Hill Publishers, New York, USA. 